\title{
International Journal of Ayurveda
} and Pharma Research

\author{
Review Article
}

\section{A REVIEW ON THE ROLE OF HOMOEOPATHY IN EPIDEMICS AMIDST COVID-19 CRISIS}

\section{Ashish Shivadikar \\ Research Officer (H), S-2, Regional Research Institute (H), Gudivada, Dr.GGH Medical College Campus, Eluru road, Krishna district, Andhra Pradesh.}

\begin{abstract}
It is a challenging time for the entire medical world to manage Coronavirus diseases 2019 (COVID-19). The past few decades there is increase of epidemic diseases, with increase loss of lives due to rapidly spreading devastating epidemics; there is a need for protective immunization and prevention. The great hope in the control of infectious diseases is always vaccine. Vaccines have played an important part in the reduction of communicable diseases. However, Vaccines are continually monitored for safety, and like any medication, vaccine can cause side effects. Homoeopathy has been reportedly used with variable degree of success in influenza, cholera and other epidemics for 200 years. Homoeopathy has been used both therapeutically and /or prophylactic with success in past, using different approaches like Genus epidemicus, nosodes, and homoeopathic formulations.
\end{abstract}

KEYWORDS: Homoeopathy, Epidemic, Nosodes, Genus epidemicus, COVID-19.

\section{INTRODUCTION}

During December 2019, a novel Betacoronavirus provisionally named 2019 novel coronavirus (2019-nCoV), and subsequently officially renamed severe acute respiratory syndrome coronavirus 2 (SARS-CoV-2) by the International Committee on Taxonomy of Viruses (ICTV), causing coronavirus disease 2019 (or COVID-19), was associated with a cluster of respiratory tract infections in Wuhan, Hubei Province, China and has rapidly spread across continents.[1] On $30^{\text {th }}$ January 2020, the WHO declared the Chinese outbreak of COVID-19 to be a Public Health Emergency of International Concern posing a high risk to countries with vulnerable health systems. ${ }^{[2]}$ In India, the first case was detected on $30^{\text {th }}$ January 2020 , thereafter day by day the number of cases of COVID-19 infection are increasing. With the spread over more than 28 states isolation and social distancing is the general measures taken up by the public promoted by the government in the form of lock down since $24^{\text {th }}$ March 2020.[3] The treatment of the patients with COVID-19 is the major challenge as mortality ranges from $3 \%$ to $4 \%$ as compared to seasonal influenza (0.1\%). Many potential drugs including ribavirin, interferon, lopinavir-ritonavir, corticosteroids, penciclovir, nitazoxanide, nafamostat, remdesivir, favipiravir, oseltamivir, azithromycin, baricitinib, and traditional Chinese medicine are being explored. However, as of now, there is no United States Food and Drug Administration approved drug or vaccine available for COVID-19.[4] Development of any vaccine for immunization is the end result of years of discovery and development. Only a tiny percentage of candidate vaccines progress to licensing, making the costs of vaccine research and development extremely high. The vaccine development and testing follow a standard set of steps beginning with exploratory stage which includes the basic laboratory research and often lasts for 2-4 years.[5] Vaccination is one of the great public health achievements of human history. Vaccines used in national immunization programmes (NIPs) are considered safe and effective when used correctly. Vaccines are, however, not riskfree and adverse events will occasionally occur following vaccination.[6]

The preventive aspect of Homoeopathy is well known, and historically, Homoeopathy has reportedly been used for prevention during the epidemics of Cholera, Spanish Influenza, Yellow fever, Scarlet fever, Diphtheria, Typhoid etc. The approach to prevention in Homoeopathy is two-pronged. Homoeoprophylaxis or, prevention through Homoeopathy, can either be met through Genus Epidemicus (GE), which means a remedy which is found to be curative in the majority of cases of the same disease is also the most likely preventive for that disease; or through nosodes (medicine prepared from biological material of a disease). The former is identified through observation of several cases of an epidemic disease, and analysing the symptomatology 
of those cases for the most indicated medicine. This medicine is considered to be the preventive medicine for the ongoing epidemic of that disease. The latter, on the other hand, once prepared through homoeopathic procedure, is considered a preventive for the disease it is prepared from, regardless of the overall presentation of that disease, which happens to change from time to time.[7] Also patients treated for influenza like illness with homeopathic medications are more satisfied with their treatment than other patients. ${ }^{[8]}$

\section{History of Homoeopathic prophylactic}

Preventive use of Homoeopathy was first applied in 1801 during an epidemic of scarlet fever in Konigslutter, Germany, when Hahnemann prescribed a single dose of Belladonna, as the GE to susceptible children in the town with $100 \%$ success. ${ }^{[9]}$ Camphora, Cuprum metallicum and Veratrum album proved successful in different stages of the Cholera epidemic (1831-1832) and it was reported that mortality rate in European homoeopathic hospitals was 7\%-10\%, whereas with conventional treatment, it varied between 40 and 80\%. Camphora saved another epidemic of Cholera (1846), where mortality rate amongst patients treated with Homoeopathy was $5 \%-16 \%$ as compared to $54 \%-90 \%$ amongst patients treated conventionally.[10-14] 2806 patients were treated prophylactically with Variolinum 30 (a nosode) for prevention of smallpox in Iowa. Of the 547 patients definitely exposed, only 14 developed the disease. Efficacy rate was $97.5 \% .{ }^{[15]}$

\section{Genus Epidemicus}

In epidemics the medicine which covers most of the symptoms is declared as Genus Epidemicus and is recommended for use as prophylaxis, as well as treatment. There is anecdotal evidence that homeopathy was successful during the Spanish flu epidemic of 1918 to 1919, in which at least 20 million people died worldwide, more than 500,000 in the United States alone. According to the historian Julian Winston, the death rates for patients treated with Homeopathy were 1 to $2 \%$ compared with 30 to $60 \%$ mortality for those treated by conventional physicians. The genus epidemicus for the Spanish flu, according to Winston, was Gelsemium. ${ }^{[16]}$ For a series of dengue fever outbreaks over the years in Brazil (2001-2012), identified GE Eupatorium perfoliatum or a combination of remedies based on the epidemic picture could significantly control the occurrence by 80\%-90\%.[17] A study by Rejikumar et al. in 2006 on 1061 people living in parts of Kerala badly affected by Chikungunya epidemic showed prevention in 82.19\% people after administration of homoeopathic medicine Eupatorium perfoliatum 200C (three doses daily for 5 consecutive days).[18]

\section{Nosodes}

Nosodes are used in different settings, practice as therapeutic remedy and public health as homoeoprophylaxis during epidemic outbreak of diseases. During an outbreak of meningococcal meningitis in 1974 at Guaratingueta, Sao Paulo, Brazil, homoeoprophylaxis with Meningococcinum nosode was administered to 18,640 people. This study showed 95\% effectiveness over 6 months.[19] A similar study during an outbreak of this condition in the city of Blumenau, Brazil, in 1998, saw the nosode administered voluntarily to 65,826 people aged between 0 and 20 over 3 days at the public health clinics. The programme provided $95 \%$ protection from the severe bacterial infection after 6 months and $91 \%$ after 12 months, and the results were statistically significant.[20] In 1987, Fox concluded that Pertussin 30c as a prophylactic for whooping cough was $82 \%$ effective. However, the results reported by English though have tendency to prevent whooping cough were statistically insignificant. Both studies suggested for large sample trials.[21,22] During epidemic in France from 1984-1987, Oscillococcinum 200C taken twice daily for 5 days significantly increased the rate of cure within two days $(n=478$, 237 treated by medicine and 241 on placebo), absence of symptoms at 48 hours, relative risk estimate significantly favours homeopathy $(\mathrm{p}=0.048)$, no pain and no fever $(\mathrm{p}=0.048)$, recovery rate (headache, stiffness, articular pain, shivering reduction) at 48 hours better in homeopathy group $(p=0.032) .{ }^{[23]}$ A randomised double-blind prospective study of thirty participants compared standard vaccination to Influenzinum homoeopathic medicine for 13 weeks. This study found equal efficacy of the two methods in the prevention of influenza; however, the vaccination cohort experienced greater adverse reactions.[24] In another blinded randomised controlled trial in children in Brazil, wherein the homoeopathic medications used were either a homoeopathic nosode prepared from intact influenza A virus, or a homoeopathic complex frequently used in that region for influenza. This study showed a statistically significant reduction of influenza episodes in children receiving either of the two homoeopathic treatments versus placebo.[25]

The study, conducted in 2007, used homoeo prophylactic interventions against the condition in three provinces of Cuba. They prepared a homoeo prophylactic formulation from dilutions of four circulating strains of leptospirosis and administered orally to 2.3 million persons at high risk in an epidemic in a region affected by natural disasters. After the homoeo prophylactic intervention, a significant decrease of the disease incidence was 
observed in the intervention regions compared to the non-intervention regions. The results were reevaluated, and the findings were consistent with those of the earlier results.[26] During a dengue outbreak in Delhi in 1996, the Central Council for Research in Homoeopathy distributed Dengueinum 30 (prepared from the serum of person suffering from dengue fever) to 39,200 people who were not affected and residing in the adversely affected areas for preventing the dengue. Follow-up after 10 days revealed appearance of fever, headache and body ache in five persons only.[27] A homoeopathic drug Malaria officinalis 200 was used for the mass prophylaxis for malaria in high malaria transmission season in selected 28 villages of district Shahdol of Madhya Pradesh state. Of the 28 villages, seven $(25 \%)$ reported malaria case incidence $\leq 2$ in 6-month period (July-December 2016). In the previous year, $23(82 \%)$ villages reported the incidence of malaria as more than 2 in the same time period. Hence, the number of villages with 'bi-annual malaria case incidence rate' was reduced by $57 \%$. ${ }^{[28]}$

\section{Homoeopathic Medicines and Immuno- modulation}

There are several homoeopathy preclinical studies which shows the immunomodulatory action of homoeopathic medicines. In a study, for the acute and subacute toxicity of dengue nosodes, changes in behaviour or mortality were observed in Wistar rats, with increased serum levels of tumour necrosis factor- $\alpha$, interleukin (IL) IL-1 $\beta$, IL-6, IL-12 and IgM, although there were no signs of toxicity. ${ }^{[29]}$ A study with Trypanosoma cruzi nosode on mice of different ages, infected with the concerned protozoa, modulated the inflammatory response with increased apoptosis and decreased serum levels of transforming growth factor-beta (TGF- $\beta$ ). ${ }^{[30]}$ Psorinum, when tested in 6x potency on cancer cell lines, showed greater anticancer effects in A549 cells than in others. It triggered apoptosis in A549 cells via both up and down regulations of relevant signal proteins, including p53, caspase-3, Bax and Bcl-2.[31] A nosode prepared from the infectious influenza A virus (H3N2) on cell lines altered the cellular and biochemical features of MDCK and J774G8 cells.[32] Arsenic album has shown to affect HT29 cells and human macrophages. Also, it showed $\downarrow N F-\kappa B$ hyperactivity (reduced expression of reporter gene GFP in transfect HT29 cells), $\downarrow$ TNF- $\alpha$ release in macrophages. ${ }^{[3]}$ Preclinical studies conducted by CCRH in collaboration with School of Tropical Medicine, Kolkata, and in molecular studies conducted in collaboration with King's George Medical University, Lucknow, observed protective effects through antiviral properties of Belladonna in
Japanese encephalitis.[34-35] There are several other studies published which shows the immunomodulatory potential of homoeopathic medicines in preclinical studies. ${ }^{[36-41]}$

\section{Homoeopathic Formulations}

There are several reports, where combinations of homoeopathic remedies that are commonly prescribed for a specific disease were used to treat people during an epidemic. In Cuba, 25,000 patients who tested positive for dengue were treated with homoeopathic complex containing medicines Bryonia Alba, Eupatorium p., Gelsemium s. and dengue nosode with significant improvement in clinical condition and reduction in days of stay at hospital.[42] In Pakistan, a homoeopathic complex of 10 medicines including Bryonia alba, Rhus toxicodendron, Gelsemium sempervirens, Aconitum napellus, Eupatorium perfoliatum, China boliviana, Hamamelis, Citrullus colocynthis, Crotalus horridus and Phosphorus was given to 25 patients of dengue fever and the mean values of each of the criteria of both homoeopathic and standard treatment groups were compared. Better results were seen in the blood values within a week of prescription, as opposed to the standard maintenance therapy.[43] In early 2007, facing the challenge of controlling an outbreak of dengue, the Secretary of Health of the county of Macae, Rio de Janeiro, Brazil, carried out a "Homeopathy Campaign against Dengue." 156,000 doses of homoeopathic remedy were freely distributed in April and May 2007 to asymptomatic patients, according to the notion of "epidemic genus. The remedy used was a homoeopathic complex against dengue containing Phosphorus $30 \mathrm{cH}$, Crotalus horridus $30 \mathrm{cH}$ and Eupatorium perfoliatum $30 \mathrm{cH}$. The incidence of the disease in the first 3 months of 2008 fell by $93 \%$ in comparison to the corresponding period in 2007, whereas in the rest of the state of Rio de Janeiro there was an increase of $128 \%{ }^{[44]}$ In India, homoeoprophylaxis is also being used in the management of the Japanese Encephalitis epidemic in during the year 1999-2003, the government of Andhra Pradesh adopted Belladonna-Calcarea carbonica-Tuberculinum bovinum (BCT) regimen as preventive and the response was encouraging. The death rate was nil in the BCT distributed areas. [45]

\section{Homoeopathic research in epidemics}

In 2007, CCRH conducted preventive trial, where homoeopathic medicine Bryonia 30C was distributed as a preventive to 19,750 people in Kerala and Bryonia alba 30C was found to be better than placebo in decreasing the incidence of Chikungunya in Kerala. ${ }^{[46]}$ Multicenter, single blind, randomized, placebo controlled study was conducted by CCRH to evaluate the effect of homoeopathic 
medicines in the treatment of Influenza like illness and to compare the efficacy of LM (50 millesimal) potency vis-à-vis centesimal (C) potency. In LM group $(n=152), C$ group $(n=147)$ or placebo $(n=148)$ group. The study revealed the significant effect of individualized homoeopathic treatment in the patients suffering from ILI with no marked difference between LM and Centesimal groups. The medicines which were commonly prescribed were: Arsenic album, Bryonia alba, Rhustox., Belladonna, Nux vomica, Sepia, Phosphorus, Gelsemium, Sulphur, Natrum mur. and Aconitum napellus.[47] Central Council for Research in Homoeopathy carried out research studies for prevention and treatment of JE during its epidemics in eastern parts of U.P. in 1989, 1991 and 1993. Belladonna 200, single dose was distributed as preventive to $3,22,812$ persons in 96 villages in three districts of U.P. In a follow up of 39,250 persons, none of them reported any signs and symptoms of Japanese encephalitis.[48] Robert $\mathrm{T}$ Mathie, et al. observed that during, the 2009 A/H1N1 influenza pandemic in India, several prominent symptoms and symptom/medicine associations, particularly temperature >38_C + cough + runny nose, were associated with Arsenicum album. ${ }^{[49]}$

In the recent years, successes of adjunct homoeopathic treatment in epidemics of dengue and acute encephalitis syndrome have been reported in studies conducted by CCRH. Adjuvant homoeopathic treatment given to dengue haemorrhagic cases at a tertiary care hospital during the dengue outbreak in 2015 in Delhi showed that patients who received Homoeopathy had rapid rise in platelet count and less number of days of hospital stay compared to those who received standard care alone. Similarly, in acute encephalitis syndrome/Japanese encephalitis, Homoeopathy as an adjuvant to the Institutional Management protocol (IMP) could decrease death rate by $15 \%$ in comparison to those who received only IMP.[50-51] Another prospective observational study was conducted on 126 patients of Chikungunya in Chikungunya Fever (CF) and in Post-Chikungunya Chronic Arthritis (PCCA) in a Delhi Government Homeopathic Dispensary for a period of 6 months. A single homeopathic medicine was prescribed for each patient after case taking with the help of Materia Medica and/or Repertory. The study resulted in complete recovery was seen in $84.5 \%$ CF cases in a mean time of 6.8 days. $90 \%$ cases of PCCA recovered completely in a mean time of 32.5 days. [52]

\section{Veterinary Homoeopathy}

Few animal studies were conducted to assess the prophylactic effect of Homoeopathic medicines in diseases like Anthrax, Colibacillosis, Bovine mastitis etc. A study by Dabbir BR. found during an Anthrax outbreak in an endemic place of India, all the sheep and goats were protected from Anthrax with a single dose of Anthracinum CH 200 both in non\endemic villages. ${ }^{[53]}$ In a review article published by Zeise and Fritz, observed that the selected studies showed a positive treatment outcome of homeopathy and possibility to reduce antibiotic use by $75 \%$ in bovine mastitis[54] In another study conducted by Coelho C. et al to assess homoeopathic treatment as preventive against colibacillosis in newborn piglets concluded that homeopathic and biotherapic treatment were more effective than antibiotics in the control of diarrhoea in newborn piglets. ${ }^{[55]}$

\section{Agro-Homoeopathy}

There are studies to support the premise that homeopathic and high dilution preparations have the potential to be effective on replacing pesticides that are used on crops and that "Similia Principle" is very useful to overcome abiotic stresses of plants. ${ }^{[56-57]}$ Another randomised study conducted on Mangifera indica (Mango), by using selected homeopathic medicines of different potencies and concentrations, inferred that all of the selected homeopathic medicines exhibited significant $(p<0.0001)$ antifungal effect against $C$. gloeosporioides at 3000 ppm on OMA contained Petri-plates. Among the tested medicines Arsenicum album showed significant $(p<0.0001)$ inhibition against $C$. gloeosporioides in controlling the disease [58].

\section{CONCLUSION}

One of the most important challenges of the public health is to control these epidemic outbreaks, which are diseases that spread rapidly and widely, affecting many individuals in the population at the same time. The recent COVID-19 outbreak has been deemed a global health emergency. The homoeopathic intervention has played a significant role in epidemics, not only by treating, but also by reducing the mortality. Administration of the specific Genus Epidemicus, derived after careful assessment of the characteristic picture of the disease across regions, and treatment of symptomatic cases with adjuvant individualised Homoeopathy, can be the most viable, safe, inexpensive and effective approach to manage COVID-19 disease outbreak globally. In India, after the Ministry of AYUSH issued an advisory early in January 2020, for prophylactic application of Arsenicum album 30, many institutions started distributing it to the masses. Cuba has also issued directions for distribution of a combination homoeopathic remedy to the unaffected population, while physicians in Hong Kong and Italy have been treating a few patients of COVID-19 with Homoeopathy. ${ }^{59}$ Homoeopathy could play important role both therapeutically and /or prophylactic with 
success in management of COVID-19. However, establishing the preventive use of Homeopathy in public health setting is a challenge. High quality safety and pre-clinical studies, as well as robust clinical research is required to be undertaken for establishing role of Homoeopathy in epidemics.

\section{REFERENCES}

1. T.Lupia et al. 2019 novel coronavirus (2019-nCoV) outbreak: A new challenge. Journal of Global Antimicrobial Resistance. 21 (2020) 22-27.

2. World Health Organization, Novel Coronavirus (2019-nCoV), Situation Report - 12(2020).

3. Guidelines for homoeopathic practitioners for COVID 19. Ministry of AYUSH, Govt. Of India. 2020

4. Badyal DK, Mahajan R. Chloroquine: Can it be a Novel Drug for COVID-19. Int J App Basic Med Res 2020;10:128-30.

5. Manchanda RK. Vision for the prevention of infections using Homoeopathy. Indian J Res Homoeopathy 2016;10:219-22.

6. World Health Organization. Vaccine safety basic learning manual. 2013.

7. CCRH. Epidemics- IMR project Available from: https://www.ccrhindia.nic.in/ (Last accessed on: 25.6.2020).

8. Stephane Vincent, et al. The journal of alternative and complementary medicine. Volume 19 , Number 2, 2013, pp. 146-152.

9. Marino R. Flu pandemics: Homeopathic Prophylaxis and Definition of the Epidemic Genius. Int J High Dilution Res 2009;8:100-9.

10. Hoover TA. Homeopathic prophylaxis: Fact or fiction. J Am Inst Homeopath 2001;94:168-75.

11. Shalts E. Consistently proven effective. In: The American Institute of Homeopathy Handbook for Parents. San Francisco: Jossey-Bass; 2005.p. 33-40.

12. Dudgeon RE. Hahnemanns discovery of the prophylactic powers of belladonna in scarlet fever allopathic testimony to this prophylactic. In: Dudgeon RE, editor. Lectures on the Theory \& Practice of Homoeopathy. New Delhi: B Jain Publishers; 2002. p. 540-4.

13. Von Bönninghausen CM, editor. Brief instructions for non-physicians concerning the prophylaxis and treatment of Asiatic cholera. In: The Lesser Writings of C.M.F. von Boenninghausen. Rep ed. New Delhi: B Jain Publishers; 2005. p. 299-308.

14. Shepherd D. Homoeopathy in epidemic diseases. Saffron Walden: C.W.Daniel Company Ltd.; 1996.

15. American Institute of Homoeopathy, Chicago, Transactions of the 63rd session of the American
Institute of Homeopathy, Norfolk, VA., 1907. Pages 547-567.

16. Jacobs J. Homeopathic prevention and management of epidemic diseases. Homeopathy 2018;107:157-60.

17. Marino R. Homeopathy and collective health: The case of dengue epidemics. Int J High Dilution Res 2008;7:179-85.

18. Rejikumar R, Dinesh RS. A Study on the Prophylactic Efficacy of Homoeopathic Preventive Medicine Against Chikungunya Fever. Available on: http://www.similima.com/pdf/ efficacychiunguna-kerala.pdf (Last accessed on: 27.6.2020)

19. Castro D, Nogueira G. Use of the nosode meningococcinum as a preventive against meningitis. J Am Inst Homeopath 1975;68:211-9.

20. Mroninski C, Adriano EJ, Mattos G Meningococcinum: Its protective effect against Meningococcal disease. Homeopath Links 2001; 14:230-4.

21. Fox AD. Whooping cough prophylaxis with Pertussin 30. Br Homeopath J 1987;76:69-70.

22. English JM. Pertussin 30-preventive for whooping cough? A pilot study. Br Homeopath J 1987; 76:61-5.

23. P.Ferley et al, A controlled evaluation of a homoeopathic preparation in the treatment of influenza-like syndromes, British Journal of Clinical Pharmacology (1989) 27, pg No. 329-335.

24. Frost C. A double blind study on the comparative efficacy of influenza vaccination and influenzinum 7 CH. Faculty of Health Sciences, Technikon Witwatersrand; 2004.

25. Siqueira CM, Homsani F, da Veiga VF, Lyrio C, Mattos H, Passos SR, et al. Homeopathic medicines for prevention of influenza and acute respiratory tract infections in children: Blind, randomized, placebo-controlled clinical trial. Homeopathy 2016;105:71-7.

26. Golden I, Bracho G. A re-evaluation of the effectiveness of homoeoprophylaxis against leptospirosis in Cuba in 2007 and 2008. J Evid Based Complementary Altern Med 2014; 19: 155-60.

27. CCRH News Letter No.23. Dengueinum. Central Council for Research in Homoeopathy; New Delhi: 1996.

28. Pandey R, Gupta S, Singh AR, Gupta J, Kabirpanthi V. Effectiveness of medicine malaria Off 200 , as mass prophylaxis against malaria in the high-risk villages of Shahdol, Madhya Pradesh. Int Arch Biomed Clin Res 2019;5:1-6. 
29. Singh S. Safety and pharmacological aspect of homoeopathic medicine. In: Scientific convention on World Homoeopathy Day: Exploring science for 40 years. New Delhi: Central Council for Research in Homoeopathy; 2018. p. 137.

30. Sandri P, Aleixo DL, Sanchez Falkowski GJ, Nascimento Junior AD, Gomes ML, Hernandes L, et al. Trypanosoma cruzi: Biotherapy made from trypomastigote modulates the inflammatory response. Homeopathy 2015;104:48-56.

31. Mondal J, Samadder A, Khuda-Bukhsh AR. Psorinum $6 \times$ triggers apoptosis signals in human lung cancer cells. J Integr Med 2016;14:143-53.

32. Siqueira CM, Costa B, Amorim AM, Goncalves $M$, Feo da Veiga V, Castelo-Branco $\mathrm{M}$, et al. H3N2 homeopathic influenza virus solution modifies cellular and biochemical aspects of MDCK and J774G8 cell lines. Homeopathy 2013;102:31-40.

33. Bellavite P, Signorini A, Marzotto M, Moratti E, Bonafini C, Olioso D. Cell sensitivity, non-linearity and inverse effects. Homeopathy. 2015 Apr; 104(2):139-60.

34. Bandyopadhyay B, Das S, Sengupta M, Saha C, Das KC, Sarkar D, et al. Decreased intensity of Japanese encephalitis virus infection in chick chorioallantoic membrane under influence of ultradiluted Belladonna extract. Am J Infect Dis 2010;6:24-8.

35. Bandyopadhyay B, Das S, Sengupta M, Saha C, Bhattacharya N, Chinta R, et al. Suckling mice of Belladonna 200 fed mothers evade virulent Nakayama strain Japanese encephalitis virus infection Int J Microbiol Res 2011;2:252-7.

36. Cajueiroa APB, Gomaa EP, Santosa HAM, Rodriguesa IA, Tomaa HK, Araújob SM et al. Homeopathic medicines cause Th1 predominance and induce spleen and megakaryocytes changes in BALB/c mice infected with Leishmania infantum. Cytokine. 2017; 95: Available from: https:// www. sciencedirect.com/science/article/pii/S10434666 17300467 (Last accessed on: 30.6.2020).

37. Santana FRD, Coelho CP, Cardoso TN, Hurtado ECP, Benites NR, Laurenti MD et al. Modulation of inflammation response to murine cutaneous Leishmaniasis by homeopathic medicines: Antimonium crudum 30cH. Homeopathy. 2014; 103: Available from: https://doi.org/10.1016/j. homp.2014.08.006 (Last accessed on: 1.7.2020).

38. Santana FRD, Coelho CDP, Cardoso TN, Laurenti MD, Hurtado ECP, Bonamin LV.Modulation of inflammation response to murine cutaneous Leishmaniosis by homeopathic medicines: Thymulin 5cH. Homeopathy. 2014; 103: Available from: DOI: 10.1016/j.homp.2014.08.002 (Last accessed on: 1.7.2020).

39. Sandri PF, Portocarrero AR, Ciupa L, Veiga FK, Sanchez Falkowski GJ, Benvenutti MJ et al. Clinical and parasitological assessment in mice treated with highly diluted Atropa belladonna. Int J High Dilution. 2014. 13; Available from: http://www. highdilution.org/index.php/ijhdr/article/view/73 4 (Last accessed on: 2.7.2020).

40. Jonas WB, Dillner DK. Protection of mice from Tularemia infection with ultra-low, serial agitated dilutions prepared from Francisella tularensisinfected tissue. Journal of Scientific Exploration. 2000. 14; Available from: http://citeseerx.ist. psu.edu/viewdoc/download?doi=10.1.1.543.2578 \&rep=rep1\&type=pdf. (Last accessed on: 3.7.2020).

41. Singh LM, Gupta G. Antiviral efficacy of homoeopathic drugs against animal viruses. 1985; 7: Available from: https://doi.org/10.1016/ S0007-0785 (85)80063-6. (Last accessed on: 5.7.2020)

42. Bracho G. Homoeopathy and ultradilutions: From basic evidences to practical applications. Powerpoint presented at 14th Japanese Homoeopathic Medical Association (JPHMA) Congress. 7-8 December 2013.

43. Saeed-ul-Hassan S, Tariq I, Khalid A, Karim S. Comparative clinical study on the effectiveness of homeopathic combination remedy with standard maintenance therapy for dengue fever. Trop J Pharm Res 2013;12:767-70.

44. Nunes L. Reynaldo AS. Amorim MHC. Zandonade E. Salume S. Contribution of homeopathy to the control of an outbreak of dengue in Macae, Rio de Janeiro. Int J High Dilution Res 2008;7:186-92.

45. Government of Andhra Pradesh. Japanese Encephalitis-Homoeopathic Prevention Programme. 2004.

46. Nair KR, Gopinadhan S, Sreedhara KT, Kumar BJ, Aggarwal A, Varanasi R, et al. Homoeopathic genus epidemicus 'Bryonia alba' as a prophylactic during an outbreak of chikungunya in India: A cluster-randomised, double-blind, placebo controlled trial. Indian J Res Homoeopathy 2014;8:160-5.

47. Homoeopathy in Flu-like Illness- Factsheet, Central Council for Research in Homoeopathy, Dept. of AYUSH, Ministry of Health \& Family Welfare, Govt, of India, 2015, http:// ccrhindia.org (Last accessed on: 8.7.2020).

48. Rastogi D.P., Sharma V.D. Study of Homoeopathic Drugs in Encephalitis Epidemic in Uttar Pradesh (India); Central Council for Research in 
Homoeopathy Quarterly Bulletin; 1992: 14 (3\&4): p.1-1

49. Robert T Mathie et al. Homeopathic treatment of patients with influenza-like illness during the 2009 A/H1N1 influenza pandemic in India. Homeopathy (2013) 102, 187-192.

50. Nayak D, Chadha V, Jain S, Nim P, Sachdeva J, Sachdeva G, et al. Effect of adjuvant homeopathy with usual care in management of thrombocytopenia due to dengue: A comparative cohort study. Homeopathy 2019;108:150-7.

51. Manchanda RK, Oberai P, Roja V, Singh S, Singh N, Khan $\mathrm{T}$, et al. Evaluation of homoeopathic medicines as add-on to institutional management protocol in Acute Encephalitis Syndrome: An exploratory observational comparative study. Indian J Res Homoeopathy 2015;9:34-41.

52. Wadhwani G.G. Homeopathic drug therapy Homeopathy in Chikungunya Fever and PostChikungunya Chronic Arthritis: an observational study. Homeopathy (2013) 102, 193-198.

53. Dabbir BR. Prevention of anthrax epidemic in sheep and goats with Anthracinum 200. Indian J Res Homoeopathy. 2017; 11:244-8.

54. Zeise J, Fritz J. Use and efficacy of homeopathy in prevention and treatment of bovine mastitis, Open Agriculture. 2019; 4:203-212.

\section{Cite this article as:}

Ashish Shivadikar. A review on the role of Homoeopathy in epidemics amidst COVID-19 crisis. International Journal of Ayurveda and Pharma Research. 2020;8(8):51-57.

Source of support: Nil, Conflict of interest: None Declared
55. Cideli C, Francisco S, Erlete V et al. Evaluation of preventive homeopathic treatment against Colibacillosis in swine production, International Journal of High Dilution Research; 2009; 8(29): 183-190.

56. Modolon TA; Boff P; Boff MIC; Miquelluti DJ. 2012. Homeopathic and high dilution preparations for pest management to tomato crop under organic production system. Horticultura Brasileira 30: 5157.

57. Sushobhan S, Indrani C, Arjina K, sabyasachi C. Agrohomeopathy: an emerging field of agriculture for higher crop productivity and protection of plants against various stress conditions. Available from: https://www. semanticscholar.org/(Last accessed on: 8.7.2020)

58. Ashraful A, Sanjoy A, Mahtalat A, Effectiveness of Selected Homeopathic Medicines Against Colletotrichum gloeosporioides, Asian Journal of Plant Pathology. Available from: https://www. semanticscholar.org/(Last accessed on: 8.7.2020).

59. Chaudhary A, Khurana A. A review on the role of Homoeopathy in epidemics with some reflections on COVID-19 (SARS-CoV-2). Indian J Res Homoeopathy 2020;14:100-9.

\section{*Address for correspondence Dr. Ashish Shivadikar \\ Research Officer (H), S-2 Regional Research Institute $(\mathrm{H})$, Gudivada, Dr. GGH medical college campus, Eluru road, Krishna district, Andhra Pradesh. Email: ashishshivadikar@gmail.com}

Disclaimer: IJAPR is solely owned by Mahadev Publications - dedicated to publish quality research, while every effort has been taken to verify the accuracy of the content published in our Journal. IJAPR cannot accept any responsibility or liability for the articles content which are published. The views expressed in articles by our contributing authors are not necessarily those of IJAPR editor or editorial board members. 